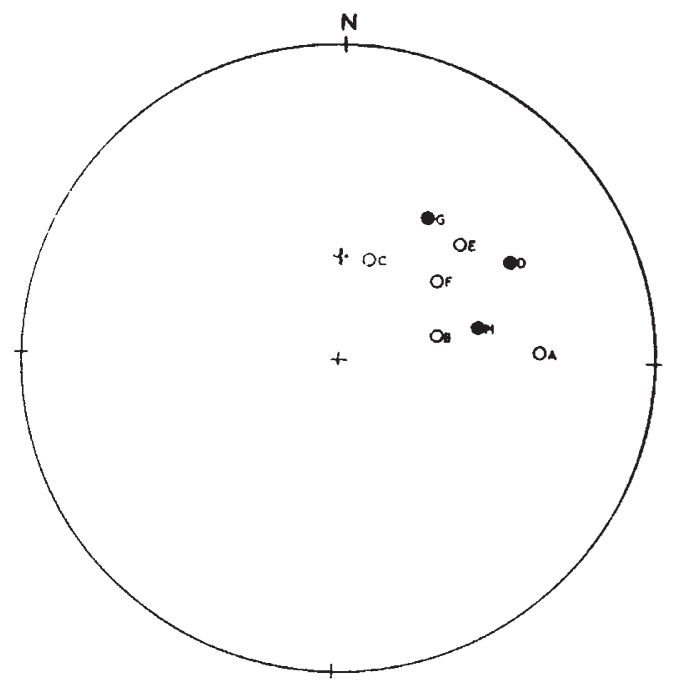

Fig. 3. Mean directions of eight flows before correcting for tilt. Cross indicates position of present dipole fleld

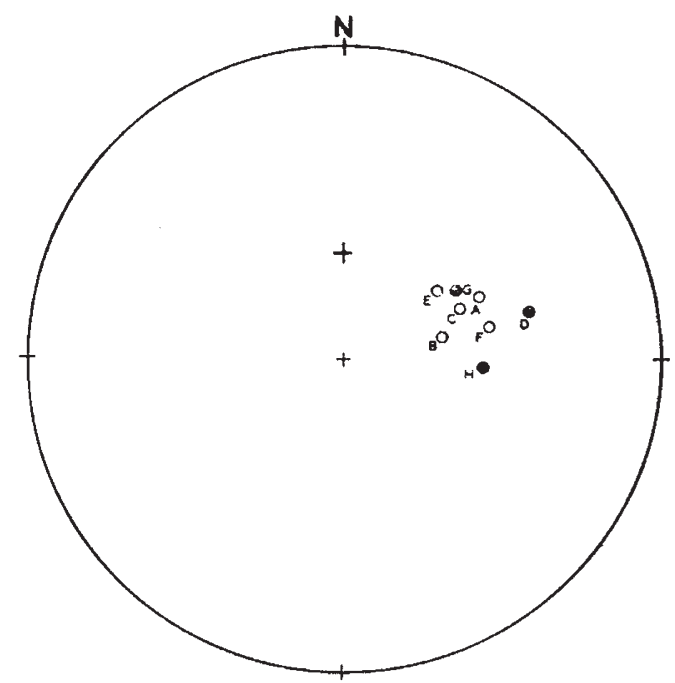

Fig. 4. Mean direction of eight flows after correcting for tilt

hundreds of feet of sediments associated with the flows, the eight flows may be considered a sampling which is random with respect to the secular variation, and Fisher's statistical method applied to give a mean direction of north $70^{\circ}$ east and $55^{\circ}$ down, with $\lambda_{95}=7^{\circ}$. (Fisher's model is not rigorously applicable to the analysis of a set containing anti-parallel directions, but is used here for comparative purposes.) The combined fifty-seven samples may also be treated by Fisher's method to give a direction of north $67^{\circ}$ east and $56^{\circ}$ down, with $\lambda_{96}=31^{\circ}$. The former is regarded as the more valid procedure, and the field thus computed is such as would be produced by an axial dipole field with a pole at latitude $37^{\circ}$ north and longitude $50^{\circ}$ west. This pole lies about $30^{\circ}$ north-east of the average pole found by Clegg et al. from the Deccan 'Traps ${ }^{4}$, which are probably slightly older. It differs by a greater distance from the Eocene poles computed from European data ${ }^{5}$.

These measurements suggest the desirability of additional measurements in the early Tertiary in order to establish the rate of variation of the average field. From this we may be able to determine the accuracy in dating which is necessary for intercontinental comparisons of directions of remanent magnetization.

I wish to acknowledge the assistance of P.D. Snavely of the U.S. Geological Survey in planning the field work, the financial support of the Institute of Geophysics, and the encouragement of Dr. John Verhoogen.

Arran Cox

Department of Geology, University of California, Berkeley 4, California. Jan. 2. 1 Snavely, P. D., and Baldwin, E. M., Amer. Assoc. Pet. Geol. Bull.,
32, 806 (1948).

2 Doell, R. R., Trans. Amer. Geophys. Union, 37, 156 (1956).

${ }^{8}$ Graham, J. W., J. Geophys. Res., 54, 131 (1949).

- Clegg, J. A., Deutsch, E. R., and Griffiths, D. H., Phil. Mag., Ser. 8, 1,419 (1956).

${ }^{5}$ Hospers, J., Nature, 173, 1183 (1954).

\section{Variation with Pressure of the Permittivity of Polythene}

IN connexion with the recent letter from Reitzel ${ }^{1}$, some measurements made in 1954 of the variation with pressure of the permittivity of polythene may be of interest. For these measurements, disks of polythene carried aluminium electrodes (which had been evaporated on) and were immersed in oil to which hydrostatic pressure, of up to $600 \mathrm{kgm} . / \mathrm{cm} .{ }^{2}$, was applied. One electrode on each disk was of smaller diameter than the disk itself, so that most of the stray capacitance at the edge of the disk was through polythene subjected to the same pressure as the rest of the specimen.

The results showed that the effect in various types of polythene, and mixtures with small amounts of other polymers, was similar; and that the main change of permittivity is that caused by the compression of the material. The remaining effect, interpreted as a variation in the polarizability $\alpha_{\text {, is }}$ given by

$\frac{1}{\alpha} \frac{\mathrm{d} \alpha}{\mathrm{d} P}=\frac{3 \varepsilon}{(\varepsilon-1)(\varepsilon+2)} \frac{1}{C} \frac{\mathrm{d} C}{\mathrm{~d} P}-\varkappa\left[1-\frac{\varepsilon}{(\varepsilon-1)(\varepsilon+2)}\right]$

where $C$ is the capacitance of a sheet specimen; or. for polythene, in which $\varepsilon=2 \cdot 29$,

$$
\frac{1}{\alpha} \frac{\mathrm{d} \alpha}{\mathrm{d} P}=1.24 \frac{1}{C} \frac{\mathrm{d} C}{\mathrm{~d} P}-0.59 x
$$

The term $\frac{1}{C} \frac{\mathrm{d} C}{\mathrm{~d} P}$ was found to be $12 \cdot 2 \times 10^{-6}$ per

$\mathrm{kgm} . / \mathrm{cm} .{ }^{2}$; the compressibility of polythene at these pressures was taken as $31 \times 10^{-6}$ per $\mathrm{kgm} . / \mathrm{cm} .^{2}$ The term $\frac{1 \mathrm{~d} \alpha}{\alpha \mathrm{d} \bar{P}}$ is therefore $-3 \times 10^{-6}$ per $\mathrm{kgm} . / \mathrm{cm} .^{2}$, somewhat less than the earlier values mentioned by Reitzel; but as it arises only as the difference of two much larger terms, and as the compressibility of polythene is known to vary with pressure, the accuracy of this result cannot be good.

\section{A. C. LYNCH}

P. L. Parsons

Post Office Engineering Research Station, Dollis Hill, London, N.W.2. Jan. 22.

${ }^{1}$ Reitzel, J., Nature, 178, 940 (1956). 